\title{
APPLIED LINGUISTICS IN ITS DISCIPLINARY CONTEXT
}

\author{
Anthony J. Liddicoat, University of South Australia
}

\begin{abstract}
Australia's current attempt to develop a process to evaluate the quality of research (Excellence in Research for Australia - ERA) places a central emphasis on the disciplinary organisation of academic work. This disciplinary focus poses particular problems for Applied Linguistics in Australia. This paper will examine Applied Linguistics in relation to this issue of discipline in two ways. First, it will examine ways in which Applied Linguistics has articulated for itself its disciplinary nature. In most formulations of the focus of Applied Linguistics, the emphasis has not been on identifying a discipline, but rather on identifying an area of focus. Such formulations necessarily cover a very diverse range of research methods, theories, etc. This approach can be seen as one of emphasising diversity and breadth within the field. Other attempts have been made to characterise Applied Linguistics in more discipline-like terms. Such broad characterisations however conceal a high degree of internal diversity. Applied Linguistics does not appear to be a 'discipline' but rather an interdisciplinary field of enquiry. Second, the paper will examine some possible implications of the diversity of Applied Linguistics for how it is positioned through the ERA process.
\end{abstract}

\section{INTRODUCTION}

The Excellence in Research for Australia (ERA) process is constructed in terms of academic 'disciplines' as organising categories for research and all research is understood primarily in terms of its inclusion in a discipline:

The unit of evaluation for ERA is the research discipline for each eligible institution. (Australian Research Council [ARC], 2008, p. 2)

ERA is a disciplinary research assessment exercise. (ARC, 2008, p. 3)

In designating disciplines as its core area of focus, ERA is locating the process of research evaluation within a broader conceptualisation of the nature of discipline. This paper will discuss some issues in understanding discipline as an organising category in academic work in general and then review how Applied Linguistics has been understood as a discipline by Applied Linguistics. It will then examine how the notion of discipline 
is being understood within the ERA process and discuss some of the consequences that this has for Applied Linguistics in Australia in the context of ERA.

\section{DISCIPLINES AS CONSTRUCTS OF ACADEMIC WORK}

Disciplines have historically been understood as observable categories for understanding the organisation of the process of research, teaching and other aspects of scholarship, as 'means and techniques for scrutinising the world and producing knowledge that is both new and valid' (Appadurai, 1996, p. 32). The idea of discipline is a highly politicised, ideological framing of the nature of academic work and identification of an area of academic work as a discipline is not simply a categorisation of activity but an ideological construction of its place with the academy.

To call a field a 'discipline' is to suggest that it is not dependent on mere doctrine and that its authority does not derive from the writings of an individual or a school, but rather from generally accepted methods and truths (Shumway and Messer-Davidow, 1991, p. 202).

Disciplinarity, therefore, has had tied to it a sense of competence and authority within academic practice. It has been a categorisation of academic work which implies standards of rigour in theory and practice which are enforced on members of the discipline by members of the discipline:

A discipline is, above all, a community based on inquiry and centered on competent investigators. It consists of individuals who associate in order to facilitate intercommunication and to establish some degree of authority over the standards of that inquiry (Geiger, 1986, p. 29).

Disciplines, according to Geiger therefore have had two key functions which are achieved through the association of academics. The first function is to enable communication about knowledge in areas of common interest, or disciplines as discourse communities in Swales' (1992) terms. The second function is to allow for regulation, for delimiting who can be said to be a practitioner of a particular discipline and what constitutes appropriate practice of the discipline (c.f. Parker, 2002). This means that disciplines can be characterised by processes of association and dissociation: that is forces which lead to grouping together of academics in order to constitute the practice of the discipline and forces which lead to separating those who practice the discipline from those who do not: 
The intellectual eco-system has with time been carved up into 'separate' institutional and professional niches through continuing processes of boundary-work designed to achieve an apparent differentiation of goals, methods, capabilities and substantive expertise (Gieryn, 1983, p. 783).

That is, disciplines have tended to construct disciplinary knowledges as specialised and discrete so that disciplines come to be seen as inherently bounded areas of enquiry. Disciplines are a form of demarcation of academic territory and claims of ownership of domains of enquiry. One concomitant outcome of the territoriality of disciplines is that those disciplines which are seen as having closely defined boundaries tend to be seen as more coherent than those which do not:

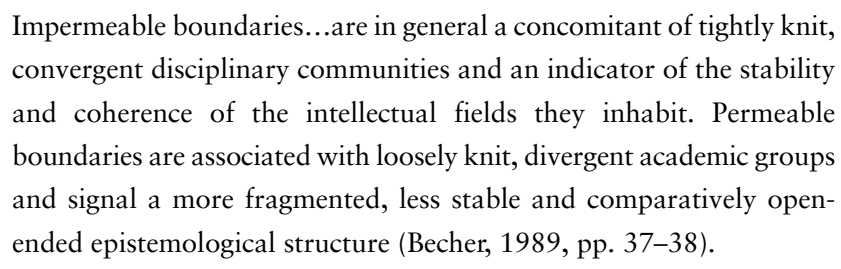

As bounded categories, disciplines may become discrete units of organisation which become available for administrative purposes: 'a discipline is at bottom nothing more than an administrative category' (Jencks and Riesman, 1968, p. 523). That is, the boundaries around academic work, which result from processes of identification and differentiation in the grouping of academics around fields of knowledge, come to be used for other purposes. Disciplines have the potential to move from expressions of academic understanding the nature and coherence of research in particular domains to become units which are applied externally to manage academic work. In this context, the idea that disciplines function to regulate standards of academic work becomes translated into the idea of the discipline as unit of evaluation and the tools of evaluation available for the discipline to regulate access become the means of regulating the discipline itself: ' $l e$ regard hiérarchique, la sanction normalisatrice et leur combinaison dans un procédure qui leur est spécifique, l'examen' (Foucault, 1975, p. 201). ${ }^{1}$ ERA in this sense is the application of the examination to disciplines themselves. 


\section{APPLIED LINGUISTICS AS A DISCIPLINE}

\section{THE SCOPE OF APPLIED LINGUISTICS AS AN ACADEMIC FIELD}

It is a commonplace of writing on Applied Linguistics to observe that the field is difficult to define (see for example Brumfit, 1997; V. Cook, 2006; Davies, 2007; Grabe, 2002; Kaplan, 2002; Sarangi and van Leeuwen, 2003; Widdowson, 2005). The reasoning for this has been that Applied Linguistics permits a broad frame of activity and that this breadth makes definition difficult. Attempts at definition tend to identify an area of focus for Applied Linguistics work, which is developed in broad, macro-level terms:

theoretical and empirical investigation of real world problems in which language is a central issue (Brumfit, 1997, p. 93)

problems in the world in which language is implicated (G. Cook, 2002, p. 5)

a practice-driven discipline that addresses language based problems inreal world contexts (Grabe, 2002, p. 10).

Such attempts at definition focus on two core elements of what is seen as constituting work in Applied Linguistics: that it is concerned with language and with problems which exist in the real world. For Grabe (2002), this combination of language and real world problems is the constituent feature of Applied Linguistics as a discipline although he defends the disciplinarity of Applied Linguistics in a number of other ways, largely related to sense of professional identity and practices of communication and organisation. Such general formulations of the nature of Applied Linguistics necessarily cover a very diverse range of research methods, theories, etc. and indicate little about the nature of Applied Linguistics except at the most general level. In working through the consequences of understanding a field of academic work in such a broad way, two competing approaches can be determined: an approach which emphasises and encapsulates diversity and one which seeks to restrict and focus the scope.

An obvious expression of the trend to promote diversity in Applied Linguistics can be seen in the large number of Scientific Commissions established by the International Association of Applied Linguistics (Table 14.1). ${ }^{2}$ This list demonstrates a wide range of activities which have been included under the umbrella of Applied Linguistics but also shows that the list, which has expanded over time, is not a coherent organisation of work in Applied Linguistics. Many of the areas of focus overlap and some of the areas listed, 
such as Sociolinguistics, Psycholinguistics and Lexicography, are commonly considered to be independent field of research outside the context of Applied Linguistics.

\begin{tabular}{|l|l|}
\hline Adult language learning & $\begin{array}{l}\text { Language and the media } \\
\text { Child language }\end{array}$ \\
Communication in the professions & $\begin{array}{l}\text { Language contact and language change } \\
\text { Contrastive linguistics and error analysis }\end{array}$ \\
Discourse analysis & Language planning \\
Educational technology and language learning & Learner autonomy in language learning \\
Evaluation, assessment, and testing & Lexicography and lexicology \\
Foreign language teaching methodology and & Literacy \\
teacher education & Mother tongue education \\
Forensic linguistics & \\
Immersion education & Psycholinguistics \\
Interpreting and translating & Rhetoric and stylistics \\
Language and business & Second language acquisition \\
Language and ecology & Sign language \\
Language and education in multilingual settings & Language and gender \\
\hline
\end{tabular}

Table 14.1 AILA scientific commissions

The AILA listing can be seen as an 'ostensive definition' (Davies, 2007, p. 1) creating an impression of the scope and nature of the field without seeking to constrain or limit the possibilities of the field. The list of Scientific Commissions is the result of organic growth of areas of interest among groups of people who consider themselves as having a professional identity which is encapsulated within the ambit of AILA. That is, this list of areas of focus is an ad hoc product, which is neither definitive nor exhaustive. ${ }^{3}$ In understanding such constructions of diversity, it is necessary to see the scope of Applied Linguistics as a social product of association not as a form of designed coherence. Spolsky (2005) sees the relationship between the various components of this diversity as somewhat tenuous, with Applied Linguistics not so much as a discipline but as a 'cover term for a sizable group of semi-autonomous disciplines' (p. 36). That is, there is an issue within Applied Linguistics understood as diverse practices for engaging with language problems in real world settings about how the various ways of working interrelate. Sarangi and van Leeuwen (2003) see this interrelationship in terms of communities of practice is 
which Applied Linguistics is a community of communities made up of groupings with different objects of study and using different analytic frameworks. That is, the scope of Applied Linguistics is associative, it is the result of sets of communities of practice which enter into contact with some large sense of shared enterprise. This is a view of discipline, if in fact it can be so called, in which boundaries are not established and enforced and membership is not regulated except by the desire for association. For Rampton (1997) the diverse nature of Applied Linguistics is relatively unstructured and composed of fleeting associations of differentiated others in dialogue around language:

... an open field, in which those those inhabiting or passing through simply show a common commitment to the potential value of dialogue with people who are different (Rampton, 1997, p. 14).

Appadurai (1996) makes the point that diversity is not simply plurality but the organisation of plurality: 'the economy of diversity is a managed economy' (p. 25). In at least some formulations of Applied Linguistics as a diverse focus on language problems in the real world, the notion of Applied Linguistics as a managed economy is not obvious.

The construction of Applied Linguistics as a highly diverse, organically assembled, open field of enquiry is rejected by some Applied Linguistics (for example Davies, 2007; Widdowson, 2005). For Davies (2007) such openness to diversity in understanding the scope of Applied Linguistics risks its trivialisation as a 'science of everything' (Davies, 2007 , p. 3). While not rejecting diversity per se, they reject unbounded, unstructured diversity, typically for reasons which reflect concerns for the coherence and regulation of the discipline:

\footnotetext{
The trouble with such views is that they offer no help in constructing introductory syllabuses in applied linguistics for initiates and they lack clarity as to how a determination can be made on those initiates success in demonstrating that they should be admitted to the profession (Davies, 2007, p. 2).
}

In constructing a narrower focus for Applied Linguistics, the core reference point is understood as language teaching. That is Applied Linguistics is principally an intellectual field which is concerned with language teaching, broadly understood (Bell, 1981; Davies, 2007; McDonough, 2002; Widdowson, 2005). One of the central arguments in favour of Applied Linguistics as language teaching is historical. Early formulations of Applied Linguistics were focused on language education. Grabe (2002), in his historical synopsis 
of Applied Linguistics defines the scope of the discipline in the 1950s as second language education, with some extension into first language literacy and language arts. He traces the beginning of the expansion in the focus of Applied Linguistics beyond issues relating to education to the 1970 s and escalating beyond that time. Thus, in many discussions of Applied Linguistics, Corder's (1973) view of Applied Linguistics as focusing on language teaching, including speech therapy, translation and language planning is taken as the articulation of the target of Applied Linguistics (for example Davies, 2007; Grabe, 2002).

This more restricted view of Applied Linguistics as language teaching indicates a principled approach to determining disciplinary boundaries and produces a view of a discipline with greater methodological and epistemological unity than is found in the more elaborated, diverse construction. However, such restriction means that many people who profess to be doing Applied Linguistics will not find their work represented within the narrow view. Grabe (2002) proposes accommodating the diversity of Applied Linguistics by proposing the idea of a core and a periphery within the discipline, with the core equating with language education and related areas and the periphery consisting of everything else. ${ }^{4}$ Spolsky (1978) however has proposed a different way of understanding the place of language teaching in relation to the diversity of the field by proposing that the investigation of language education and related fields be considered as Educational Linguistics, effectively a subset of Applied Linguistics - that is as a type rather than a core. In face of the obvious diversity of the practice of contemporary Applied Linguistics, the questions it addresses and the methods it employs, attempts to formulate specific statements about what is or is not the focus of Applied Linguistics do not really serve to clarify the disciplinary nature or focus but rather to attempt to regulate patterns of inclusion and establish ways of validating some areas of work as more important than others.

\section{THE DISCIPLINARY BASE OF APPLIED LINGUISTICS}

The debate over the scope of Applied Linguistics is associated with a debate about its disciplinary nature either board understandings of the field being presented: a narrow conceptualisation of Applied Linguistics as informed by Linguistics and a broader one of Applied Linguistics as interdisciplinary. While there may be a tendency for the broad and narrow views of the disciplinary base and scope of Applied Linguistics to be correlated, the two issues do not map neatly on to each other but represent cross-cutting ways of conceptualising the field.

The interdisciplinary view of Applied Linguistics recognises that Applied Linguists work from the perspective of many different disciplinary paradigms and often cross dis- 
cipline boundaries in their work. For some writers, such as Kramsch (2000), Applied Linguistics is fundamentally interdisciplinary and developed as an interdisciplinary field '[f]ounded in Europe in the late 1950s by linguists and educators as an interdisciplinary field of research for the study of all aspects of language use' Kramsch (2000, p. 316). For others, such as Corder (1973) Applied Linguistics 'presupposes linguistics' (p. 7). The debate here is not simply one between a primarily linguistic and an interdisciplinary focus in research as all writers on Applied Linguistics see the field as requiring input from many disciplinary contexts, such as sociology, psychology, anthropology, political science, education, etc. The debate is one between those who see Applied Linguistics as having no single disciplinary focus and those who see it as fundamentally based on linguistics and incorporating other disciplinary areas. For Widdowson (2005) interdisciplinarity is simply not an issue as in his belief interdisciplinarity is not possible because no interaction of disciplines will leave those disciplines in their pristine form, one discipline will modify another to accommodate to its own perspectives.

Formulating Applied Linguistics as being in some way derived from Linguistics, as do Corder (1973) and Davies (2007), poses a problem for understanding the nature of Applied Linguistics research at present. The assertion that Applied Linguistics 'presupposes linguistics' would seem to be difficult to maintain in the context of the nature of research published as 'Applied Linguistics' which seems to own little to Linguistics as an informing discipline, for example work on language maintenance based on the work of Bourdieu (Bourdieu, 1982)..$^{5}$ It is also problematic in the context of Applied Linguistics education which in many cases gives little space to Linguistics and often less space to linguistics than to other informing disciplines, especially education (Murray and Crichton, 2009). This means that an assertion that Applied Linguistics as a discipline is in some way Linguistics may be a formulation of the discipline which sees many practitioners of Applied Linguistics disenfranchised or others unable to recognise their work within the field of Applied Linguistics. The focus here is on establishing boundaries around areas of work which can be considered to be most central or theoretically and methodologically valid rather than explaining the nature of practice.

Widdowson's (2005) resolution of the debate around disciplinarity is to reject the idea that Applied Linguistics is not actually disciplinary at all. He argues this on the basis that Applied Linguistics is concerned with real-world problems and does not involve itself in abstractions - abstractions being the hall-mark of disciplines. This view involves a somewhat idiosyncratic view of the nature of discipline and seems to imply an unstructured eclecticism in adapting theory and methods for disciplines to Applied Linguistics 
work. However, it also signals that 'discipline' as an organising construct may not be the most appropriate way of understanding Applied Linguistics.

The debate around the disciplinarity of Applied Linguistics points to two central features of work in the area. First, it acknowledges the diversity of approaches taken by Applied Linguists to address language issues. Researchers with many different disciplinary starting points contribute to the broad research profile of Applied Linguistics in Australia and internationally. In fact, Applied Linguistics is not interdisciplinary in the sense that individual researchers or research teams use multiple disciplines in conducting research, but rather that different researchers use different disciplinary bases for addressing similar topics and questions. In this sense, it may be more appropriate to consider Applied Linguistics to be pluridisciplinary (Bourguignon, 2001) in the sense of encompassing multiple disciplines working in parallel. Secondly, it recognises the coherence of Applied Linguistics is manifest in the themes that Applied Linguistics addresses rather than in the methodologies and theories used to address these issues. That is, if Applied Linguistics is a discipline, it is a discipline in terms of its focus. Such debates about scope and disciplinary focus are not necessarily inherently problematic for Applied Linguistics as disagreement and debate are common within many disciplines. However, with the advent of ERA, the existence of such debates potentially raises some issues for Applied Linguistics in Australia as disciplines are conceived in a particularly narrow way which does not match well with the nature of work in Applied Linguistics.

\section{DISCIPLINES AND ERA}

As mentioned above, the discipline is the basic unit of evaluation for ERA and even in recognising the possibility of more complex ways of understanding research work, ERA nonetheless normalises disciplinarity as the way in which research is to be understood.

ERA is a disciplinary research assessment exercise. As such, interdisciplinary research will be disaggregated to its discipline components (ARC, 2008, p. 3).

That is, interdisciplinary and other constructions of academic work as not confined within impermeable boundaries are disallowed in the ERA process and all academic work is seen as being capable of disaggregation into disciplines in ways which are not problematic to the integrity of the work itself. It is a way of seeing interdiciplinarity as an assembly of different disciplines within a body of work in such a way as each discipline remains discrete and is unaffected by the process of combining disciplinary perspectives. 
If Applied Linguistics is understood as inherently interdisciplinary, drawing on Linguistics, Sociology, Anthropology, etc., then there are potential issues for the integrity of Applied Linguistics as a field of research. The problem of discipline within the ERA context is made more complex by the ways in which the notion of discipline as a bounded entity is understood and identified.

The discipline, as the central unit of research work, is not defined but rather is understood in terms of a series of labels for particular areas of research:

The unit of evaluation for ERA is the research discipline for each eligible institution, defined by 4-digit Field of Research (FoR) codes (ARC, 2008, p. 2).

The naming of disciplines is drawn from the Australian and New Zealand Standard Research Classification (ANZSRC) (Pink and Bascand, 2008). This classification does not use the term discipline in developing its structuring of research and instead uses the notion of a research field. In fact, the ANZSRC uses the term discipline in quite different ways in relation to the codes which are developed and these in turn are different from how the terms are understood for the purposes of ERA:

The FOR has three hierarchical levels, namely Divisions (at the broadest level), Groups, and Fields (at the finest level). The Division represents a broad subject area or research discipline while groups and fields within represent increasingly detailed dissections of these categories. Divisions, Groups and Fields are assigned unique 2-digit; 4-digit; and 6-digit codes respectively. (Pink and Bascand, 2008, p. 5).

In this case, the two-digit 'Division' not the four-digit 'Group' which is identified with disciplines (or broad subject areas). This idea of discipline as the broadest level of categorisation is repeated and further explained elsewhere in the document.

Each Division is based on a broad discipline. Groups within each Division are those which share the same broad methodology, techniques and/or perspective as others in the Division. Each Group is a collection of related Fields of research. Groups and Fields of research are categorised to the Divisions sharing the same methodology rather than the Division they support (Pink and Bascand, 2008, p. 12). 
Here disciplines are defined in broad terms of shared methodologies, techniques and/or perspectives. Groups have something in common and disciplines are groupings of like others. These groupings are primarily methodological, reflecting Shumway and Messer-Davidow's (Shumway and Messer-Davidow, 1991, p. 202) idea that disciplines are characterised by generally accepted methods:

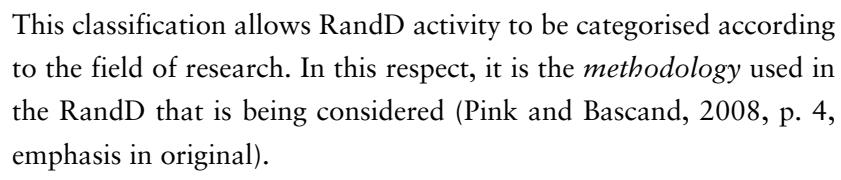

This classification allows RandD activity to be categorised according to the field of research. In this respect, it is the methodology used in the RandD that is being considered (Pink and Bascand, 2008, p. 4, emphasis in original).

This means for example that the two-digit classification, Language, Culture and Communication (20) is claimed as a grouping of: Communication and Media Studies 2001; Cultural Studies 2002; Language Studies 2003; Linguistics 2004; Literary Studies 2005 and Other Language, Communication and Culture 2099 on the basis of methodological similarity. Such a claim would however seem difficult to make for any of the 4digit Groups let alone for the two-digit Division.

\section{ERA AND APPLIED LINGUISTICS}

The approach adopted to defining disciplines in both ANZSRC and ERA are under theorised and internally inconsistent. At the same time, they construct a view of disciplines as rigid constructions with impermeable boundaries, presupposing a form of coherence in theory and practice which is not always evident within the classifications. When such classifications are applied to an area of research which is inherently diverse and which is informed by multiple disciplines, such as Applied Linguistics, there are potential problems.

The first problem that arises is the location of Applied Linguistics within the ANZSCR framework. At first glance this appears unproblematic as Applied Linguistics is assigned its own 6-digit field code: 200401 'Applied Linguistics and Educational Linguistics'. The formulation here is however potentially problematic as the collocation of 'applied' and 'educational' linguistics can be read in different ways. One possible reading is that the inclusion of 'educational' privileges an understanding of Applied Linguistics as being concerned with language teaching and that the grouping is for forms of linguistics that focus on educational matters. A second possible reading is that 'Educational Linguistics' is to be understood in Spolsky's (2005) sense and that 'Applied Linguistics' is understood as more broadly than just a language teaching focus. 
The 200401 code is also potentially problematic as it embeds Applied Linguistics as a branch of Linguistics (2004). That is, the debates in Applied Linguistics about its disciplinary basis is resolved in favour of linguistics. This means that, either research work which does not draw on linguistics as its disciplinary focus either has to be included in and evaluated as Linguistics or it has to be removed from Applied Linguistics. Interdiciplinary works is fundamentally problematic within ERA as such work is disaggregated into its disciplinary components. However, if the discipline itself is interdisciplinary it is difficult to see what the process of disaggregation is likely to be or what it achieves.

If one accepts the identification of Applied Linguistics with Linguistics a further problem emerges, because, if Applied Linguistics is understood in terms of addressing real-world language problems, it is not a methodological classification, and therefore work considered as Applied Linguistics could also be validly considered as located with other forms of Linguistics from which they draw theory and methods. For example, Computational Linguistics (200402), Discourse and Pragmatics (200403), Laboratory Phonetics and Speech Science (200404), Language in Culture and Society (Sociolinguistics) (200405) Language in Time and Space (200406) and Lexicography (200407) are all involved in the AILA Scientific Commissions given in Table 14.1 as being forms of Applied Linguistics and it is not difficult to see that Applied Linguistics research may also investigate Linguistic Structures (200408) or be included as Linguistics not elsewhere classified (200499). This is not a problem for the aggregation of this research at the 2004 level, but may mean that work which could be considered as applied linguistics may be dispersed into other sub-fields for reporting if it is not multiply coded so that the 'applied' dimension is obscured.

Given that even those authors who see Applied Linguistics as primarily connected to Linguistics see that other disciplines are involved, there is potential for applied linguistic work to be coded to other 4-digit codes. These codes could be in the Language, Culture and Communication (20) 2-digit code, that is within the same 'discipline' in ANZSRC terms, for example, Language Studies (2003), Cultural Studies (2002), ${ }^{6}$ Communication Studies (2001). ${ }^{7}$ Alternatively, they could be coded to different 2-digit codes, such as Education (13) Studies in Human Society (16), Psychology and Cognitive Sciences (17) (See Table 14.2 for examples). In this case, the research evaluation process would vary greatly for Applied Linguistics work encoded to different 2-digit codes as the possible codes cover two separate clusters - Humanities and Creative Arts and Social, Behavioural and Economic Sciences - which are evaluated using different processes and criteria. 
The diversity of Applied Linguistics and the narrowly conceived disciplinary focus of the ERA process, in combination with particular imperatives at individual institutions would seem to pose two fundamental problems for Applied Linguistics research in Australia. The first is a problem of visibility. As ERA requires reporting at 2-digit and 4-digit

\begin{tabular}{|c|c|c|}
\hline \multirow[t]{2}{*}{ Education (13) } & $\begin{array}{l}\text { Curriculum and } \\
\text { Pedagogy (1302) }\end{array}$ & $\begin{array}{l}\text { LOTE, ESL and TESOL Curriculum and Pedagogy (130207) } \\
\text { English and Literacy Curriculum and Pedagogy (130204) }\end{array}$ \\
\hline & $\begin{array}{l}\text { Specialist Studies } \\
\text { in Education (1303) }\end{array}$ & $\begin{array}{l}\text { Aboriginal and Torres Strait Islander Education (130301) } \\
\text { Comparative and Cross-Cultural Education (130302) } \\
\text { Education Assessment and Evaluation (130303) } \\
\text { Educational Technology and Computing (130306) } \\
\text { Ethnic Education (130307) }\end{array}$ \\
\hline \multirow{4}{*}{$\begin{array}{l}\text { Studies in } \\
\text { Human Society } \\
\text { (16) }\end{array}$} & $\begin{array}{l}\text { Anthropology } \\
\text { (1601) }\end{array}$ & Linguistic Anthropology (160103) \\
\hline & $\begin{array}{l}\text { Demography } \\
\text { (1603) }\end{array}$ & Migration (160303) \\
\hline & $\begin{array}{l}\text { Politics and } \\
\text { Administration } \\
(1605)\end{array}$ & Education Policy (160506) \\
\hline & Sociology (1608) & $\begin{array}{l}\text { Race and Ethnic Relations (160803) } \\
\text { Sociology of Education (160809) }\end{array}$ \\
\hline \multirow{2}{*}{$\begin{array}{l}\text { Psychology and } \\
\text { Cognitive } \\
\text { Science (17) }\end{array}$} & Psychology (1701) & $\begin{array}{l}\text { Educational Psychology (170103) } \\
\text { Developmental Psychology and Ageing (170102) }\end{array}$ \\
\hline & $\begin{array}{l}\text { Cognitive Science } \\
\text { (1702) }\end{array}$ & Linguistic Processes (170204) \\
\hline
\end{tabular}

Table 14.2 Examples of FoR codes with potential relation to Applied Linguistics

levels only applied linguistic research recorded against any 6-digit code will be aggregated to a higher level code in which the contribution of Applied Linguistics and even its existence within a research grouping will be obscured. The second is a problem of fragmentation. Applied linguistic research will be recorded in different places and so there will be work which address language problems in real world contexts that appears in different places and without necessary connection to similar work. This can be partly alleviated by multiple coding, but even this cannot ensure that fragmentation will not occur. These two issues have the capacity to interact in institutional contexts. Under the ERA process, 
it benefits institutions to concentrate research and so there is an institutional imperative to code research to where it will have the most benefit for institutional profiles. This means that, for an institution with a strong Linguistics profile, but a weak Education profile, it would be most beneficial to code Applied Linguistics as Linguistics rather as Education. Conversely for institutions with strong Education profiles but weak Linguistics profiles, it would be more beneficial to code the same research as Education rather than Linguistics. ${ }^{8}$ Moreover, given that applied linguists are located in very different institutional arrangements - Schools of Linguistics, Education, etc. - these locations may also influence coding practices and publishing choices. The idea of disciplines as administratively convenient units is likely to be more important than other, intellectually oriented, ways of understanding disciplines in the current context.

The challenge for Applied Linguistics in Australia under ERA would appear to be in maintaining a profile for Applied Linguistics as a distinctive area of research, addressing distinctive research issues and in holding together a sense of a body of research addressing language problems in real-world contexts in spite of great diversity in methodologies and disciplinary influences. The debates around Applied Linguistics as a disciplinary area which characterise Applied Linguistics internationally are significant and important debates and can be seen as reflecting a significant level of critical awareness around theory and practice in Applied Linguistics, however these same debates do not articulate well with the rigid understanding of disciplinarity which currently shapes how research in Australia is understood.

\section{ENDNOTES}

1

2 them, the examination [Authors' translation]. Linguistics work. Linguistics.

Hierarchical observation, normalising gaze and their combination in a procedure unique to

The Scientific Commissions have now been replaced by in the AILA structure by a smaller number of Research Networks which are conceived as shorter term groupings of Applied

For example, Pennycook $(2001,2004)$ expands beyond the AILA listing to include issues such as sexuality, identity, ethics, desire, difference, the construction of Otherness, etc.

McDonough (2002) has a similar division into major focuses and secondary focuses of Applied

This debate has been resolved in a significant way in the Francophone world where linguistique appliquée is considered by many people as too strongly rooted in Linguistics and is therefore of relatively little use for addressing more complex questions relating to language education. As a result, there is a clear separation between linguistique appliqué, a branch of 
Linguistics, and didactique des langues, an interdisciplinary field of research focusing on issues of second/foreign language learning and use (Véronique, 2009). For example, Multicultural, Intercultural and Cross-cultural Studies (200209). For example, Organisational, Interpersonal and Intercultural Communication (200105).

This of course applies to those areas where institutions have discretion: book, book chapter, conference and other publications and grants and may also be affected by the volume of journal publications which are coded by journal not by publication.

\section{REFERENCES}

Appadurai, Arjun. (1996). Diversity and disciplinarity as cultural artefacts. In Cary Nelson and Dilip Parameshwar Gaonkar (Eds), Disciplinarity and dissent in cultural studies (pp. 23-36). New York and London: Routledge.

Australian Research Council (ARC). (2008). ERA indicator principles. Canberra: Commonwealth of Australia.

Becher, Tony. (1989). Academic tribes and territories: intellectual enquiry and the cultures of disciplines. Milton Keynes, UK: Society for Research into Higher Education/Open University Press.

Bell, Roger T. (1981). An introduction to Applied Linguistics: approaches and methods in language teaching. London: Batsford Academic and Educational.

Bourdieu, Pierre. (1982). Langage et pouvoir symbolique. Paris: Arthème-Fayard.

Bourguignon, André. (2001). De la pluridisciplinarité a la transdisciplinarité Bulletin interactif $d u$ CIRET (Centre International de Recherches et Études Transdisciplinaires, 15, 120-127.

Brumfit, Christopher. (1997). Theoretical practice: Applied linguistics as pure and practical science. AILA Review, 12, 18-30.

Cook, Guy. (2002). Applied Linguistics. Oxford: Oxford University Press.

Cook, Vivian. (2006). What is applied linguistics? In Vivian Cook (Ed.), Obscure Writings. Retrieved 4 November, 2009, from

http://homepage.ntlworld.com/vivian.c/Writings//Papers/WhatIsAppliedLinguistics.htm.

Corder, Stephen Pitt. (1973). Introducing Applied Linguistics. Harmondsworth: Penguin.

Davies, Alan. (2007). An introduction to Applied Linguistics: from practice to theory $\left(2^{\text {nd }}\right.$ ed.). Edinburgh: Edinburgh University Press.

Foucault, Michel. (1975). Surveiller et punir: Naissance de la prison. Paris: Gallimard.

Geiger, Roger. (1986). To advance knowledge: the growth of the American research universities, 1900-1940. New York: Oxford Univeristy Press.

Gieryn, Thomas. (1983). Boundary-work and the demarcation of science from non-science: Strains and interests in professional ideologies of scientists. American Sociological Review, 48(8), 781-795. 
Grabe, William. (2002). Applied linguistics: an emerging discipline for the twentieth century. In Robert B. Kaplan (Ed.), Oxford handbook of Applied Linguistics (pp. 3-12). New York: Oxford University Press.

Jencks, Christopher; Riesman, David. (1968). The academic revolution. Garden City, NY: Doubleday. Kaplan, Robert B. (2002). Preface. In Robert B. Kaplan (Ed.), Oxford handbook of Applied Linguistics (pp. v-x). New York: Oxford University Press.

Kramsch, Claire. (2000). Second language acquisition, applied linguistics, and the teaching of foreign languages. Modern Language Journal, 84(3), 311-326.

McDonough, Steven. (2002). Applied Linguistics in language education. London: Arnold.

Murray, Neil; Crichton, Jonathan. (2009). What's in a name? Degree programs and what they tell us about 'applied linguistics' in Australia. Paper presented at the RCLC Symposium: Applied Linguistics in Australia.

Parker, Jan (2002). A new disciplinarity: communities of knowledge, learning and practice. Teaching in Higher Education, 7(4), 373-386.

Pennycook, Alastair. (2001). Critical Applied Linguistics: a critical introduction. London: Lawrence Erlbaum.

Pennycook, Alastair. (2004). Critical applied linguistics. In Alan Davies and Catherine Elder (Eds), The Handbook of Applied Linguistics (Vols. 784-807). Oxford: Blackwell.

Pink, Brian; Bascand, Geoff. (2008). Australian and New Zealand standard research classification (ANZSRC). Retrieved 27 October, 2009, from

http://www.ausstats.abs.gov.au/ausstats/subscriber.nsf/0/2A3A6DB3F4180D03CA25741A 000E25F3/\$File/12970_2008.pdf.

Rampton, Ben. (1997). Retuning in applied linguistics. International Journal of Applied Linguistics, 7(1), 3-25.

Sarangi, Srikant; van Leeuwen, Theo. (2003). Applied linguistics and communities of practice: Gaining communality or losing autonomy? In Srikant Sarangi and Theo van Leeuwen (Eds), Applied Linguistics and communities of practice (pp. 1-8). London: Continuum.

Shumway, David; Messer, Ell; , Ell; Davidow, Ell. (1991). Disciplinarity: an introduction. Poetics Today, 12(2), 201-225.

Spolsky, Bernard. (1978). Educational linguistics: an introduction. Rowley, MA: Newbury House.

Spolsky, Bernard. (2005). Is language policy applied linguistics? In Paul Bruthiaux, Dwight Atkinson, William G. Eggington, William Grabe and Vaidehi Ramanathan (Eds), Directions in Applied Linguistics (pp. 26-36). Clevedon, UK: Multilingual Matters.

Swales, John. (1992). Genre analysis: English in academic and research settings. Cambridge: Cambridge University Press. 
Véronique, G. (2009). La transformation des concepts, d'un environnement linguistique et d'un contexte national à un autre. Français dans le monde, 46, 18-32.

Widdowson, Henry G. (2005). Applied linguistics, interdisciplinarity, and disparate realities. In Paul Bruthiaux, Dwight Atkinson, William G. Eggington, William Grabe and Vaidehi Ramanathan (Eds), Directions in Applied Linguistics (pp. 12-25). Clevedon, UK: Multilingual Matters.

Cite this article as: Liddicoat, Anthony J. (2010). 'Applied linguistics in its disciplinary context'. Australian Review of Applied Linguistics 33 (2), 14.1-14.17. DOI: 10.2104/aral1014. 